\title{
Myofibrillar protein degradation in the chicken
}

\section{3-Methylhistidine release in vivo and in vitro in normal and genetically muscular-dystrophic chickens}

\author{
F. Bradley HILlGARTNER, Anne S. WILLIAMS, James A. FLANDERS, Dexter MORIN and \\ Robert J. HANSEN* \\ Department of Physiological Sciences, School of Veterinary Medicine, University of California, Davis, \\ CA 95616, U.S.A.
}

(Received 5 December 1980/Accepted 23 December 1980)

\begin{abstract}
Myofibrillar protein degradation was measured in 4-week-old normal (line 412) and genetically muscular-dystrophic (line 413) New Hampshire chickens by monitoring the rates of 3-methylhistidine excretion in vivo and in vitro. A method of perfusing breast and wing muscles was developed and the rate of 3-methylhistidine release in vitro was measured between 30 and $90 \mathrm{~min}$ of perfusion. During this perfusion period, 3-methylhistidine release from the muscle preparation was linear, indicating that changes in 3-methylhistidine concentration of the perfusate were the result of myofibrillar protein degradation. Furthermore, the viability of the perfused muscle was maintained during this interval. After $60 \mathrm{~min}$ of perfusion, ATP, ADP and creatine phosphate concentrations in pectoral muscle were similar to muscle freeze-clamped in vivo. Rates of glucose uptake and lactate production were constant during the perfusion. In dystrophic-muscle preparations, the rate of 3-methylhistidine release in vitro (nmol/h per $\mathrm{g}$ of dried muscle) was elevated 2 -fold when compared with that in normal muscle. From these data the fractional degradation rates of myofibrillar protein in normal and dystrophic pectoral muscle were calculated to be 12 and $24 \%$ respectively. Daily 3-methylhistidine excretion (nmol/day per $\mathrm{g}$ body wt.) in vivo was elevated 1.35-fold in dystrophic chickens. Additional studies revealed that the anti-dystrophic drugs diphenylhydantoin and methylsergide, which improve righting ability of dystrophic chickens, did not alter 3-methylhistidine release in vitro. This result implies that changes in myofibrillar protein turnover are not the primary lesion in avian muscular dystrophy. From tissue amino acid analysis, the myofibrillar 3-methylhistidine content per g dry weight of muscle was similar in normal and dystrophic pectoral muscle. More than $96 \%$ of the 3-methylhistidine present in pectoral muscle was associated with the myofibrillar fraction. Dystrophic myofibrillar protein contained significantly less 3-methylhistidine (nmol/g of myofibrillar protein) than protein from normal muscle. This observation supports the hypothesis that there may be a block in the biochemical maturation and development of dystrophic muscle after hatching. Free 3-methylhistidine (nmol/g wet wt.) was elevated in dystrophic muscle, whereas blood 3-methylhistidine concentrations were similar in both lines. In summary, the increased myofibrillar protein catabolism demonstrated in dystrophic pectoral muscle correlates with the increased lysosomal cathepsin activity in this tissue as reported by others.
\end{abstract}

One of the many abnormalities that characterizes hereditary muscular dystrophy in the chicken is accelerated muscle protein turnover. Protein synthesis has been reported to be elevated 2-fold in dystrophic pectoral muscle (Weinstock et al., 1969).

* To whom correspondence and requests for reprints should be addressed.
Lysosomal cathepsin activity has also been shown to be markedly increased in dystrophic muscle, inferring elevated protein catabolism in this tissue (Iodice et al., 1972; Peterson et al., 1972). By using isotopic methods, Rourke (1975) has reported increased myosin degradation in dystrophic chickens. Since no apparent degradation occurred in the normal control chickens in Rourke's study, the magnitude of the 
increased myosin degradation in dystrophic muscle was not clear. Further studies are needed to substantiate these results.

Asatoor \& Armstrong (1967) have suggested that 3-methylhistidine release from muscle and subsequent excretion from the body might be of use in determining rates of myofibrillar protein degradation in various species. Actin and myosin contain 3-methylhistidine, which is formed by the posttranslational methylation of peptide-bound histidine with $S$-adenosylmethionine (Young et al., 1972; Haverberg et al., 1974). 3-Methylhistidine is neither re-utilized for protein synthesis nor metabolized in the chicken (Cowgill \& Freeburg, 1957); therefore its rate of excretion offers a direct non-invasive method of determining the degradation rate of myofibrillar protein.

To ascertain if dystrophy increased myofibrillar protein catabolism, a study was performed to monitor the excretion of 3-methylhistidine in normal and dystrophic chickens. As a secondary objective, the effect of the anti-dystrophic drugs diphenylhydantoin and methylsergide on release of this amino acid was also investigated.

In the present paper we describe the development of a new technique to perfuse breast and wing muscles, so that 3-methylhistidine release could be measured in vitro. In addition, 3-methylhistidine was measured in the excreta of chickens to define rates of myofibrillar protein degradation in vivo.

An abstract of this work has been published previously (Hillgartner et al., 1980).

\section{Methods and materials}

\section{Animals}

Male New Hampshire chickens between 26 and 34 days of age were obtained through the generosity of Dr. B. W. Wilson and Dr. R. K. Entriken from the Department of Avian Sciences, University of California, Davis, CA, U.S.A. Two lines were used in all experiments; namely normal line 412 and genetically-related dystrophic line 413. Drug-treated chickens were obtained from Dr R. K. Entriken and Dr. B. W. Wilson after participation in a drug screening trial. Chickens were housed in wirebottomed cages that were artificially lit for $16 \mathrm{~h}$ per day and maintained at about room temperature $\left(22-24^{\circ} \mathrm{C}\right)$. Chick 'starter' (Nulaid Foods, San Leandro, CA, U.S.A.) was fed ad libitum and water was changed daily. After hatching, dystrophic chickens in the drug treatment groups were injected intraperitoneally at $12 \mathrm{~h}$ intervals with the following concentrations $(\mathrm{mg} / \mathrm{kg}$ body wt.) of diphenylhydantoin and methylsergide respectively: 10 and 2.5 (days 1-5); 20 and 5 (days 6-10); 30 and 5 (days 11-15); 40 and 10 (days 16-20); 50 and 10 (day 21-day of perfusion).

\section{Reagents}

Bovine serum albumin (Cohn fraction V), sodium pyruvate, $\mathrm{L}-(+)$-lactic acid and amino acids were purchased from Sigma Chemical Co. (St. Louis, MO, U.S.A.). Bovine serum albumin used in the perfusion medium was dialysed against deionized water for $48 \mathrm{~h}$ to remove low-molecular-weight compounds. Enzymes and biochemicals used in ATP, ADP, creatine phosphate, glucose and lactate assays were obtained from Sigma Chemical Co. All other chemicals used were of Reagent grade.

\section{Perfusion medium}

The perfusion medium, composed of bovine serum albumin, amino acids and energy substrates dissolved in buffer/salt solution, is shown in Table 1 . The mixture was passed through a $0.45 \mu \mathrm{m}$-pore-size Millipore filter before use in perfusion experiments.

\section{Surgical procedure for perfused breast and wing muscle}

The following surgical procedure confined perfusate circulation to the pectoral and wing muscles

Table 1. Breast and wing muscle perfusion medium

\begin{tabular}{|c|c|c|c|c|c|c|c|}
\hline & & & Am & 10 acids & & & \\
\hline Salts & $\begin{array}{c}\text { Concn. } \\
\text { (mM) }\end{array}$ & & $\begin{array}{c}\text { Concn. } \\
(\mu \mathrm{M})\end{array}$ & & $\begin{array}{c}\text { Concn. } \\
(\mu \mathrm{M})\end{array}$ & Other components & $\begin{array}{c}\text { Concn } \\
(\mathrm{mm})\end{array}$ \\
\hline $\mathrm{MgSO}_{4}, 7 \mathrm{H}_{2} \mathrm{O}$ & 1.0 & Alanine & 360 & Lysine & 235 & Glucose & 15.0 \\
\hline $\mathrm{Na}_{2} \mathrm{SO}_{4}$ & 1.4 & Arginine & 340 & Methionine & 80 & L-(+)-Lactic acid & 5.75 \\
\hline $\mathrm{K}_{2} \mathrm{HPO}_{4}, 3 \mathrm{H}_{2} \mathrm{O}$ & 0.7 & Asparagine & 15 & Ornithine & 65 & Sodium pyruvate & 0.55 \\
\hline $\mathrm{KCl}$ & 3.2 & Aspartate & 10 & Phenylalanine & 110 & Sodium acetate & 6.5 \\
\hline $\mathrm{CaCl}_{2}, 2 \mathrm{H}_{2} \mathrm{O}$ & 2.8 & Cysteine & 30 & Proline & 325 & Bovine serum albumin & $5 \%$ \\
\hline $\mathrm{NaHCO}_{3}$ & 37.2 & Glutamate & 80 & Serine & 570 & & \\
\hline $\mathrm{NaCl}$ & 110.2 & Glutamine & 110 & Threonine & 625 & & \\
\hline & & Glycine & 510 & Tryptophan & 80 & & \\
\hline & & Histidine & 175 & Tyrosine & 100 & & \\
\hline & & Isoleucine & 115 & Valine & 300 & & \\
\hline & & Leucine & 225 & & & & \\
\hline
\end{tabular}


of the chicken. During this operation, major blood vessels supplying internal viscera and the cranial and abdominal regions of the body were ligated followed by cannulation of the thoracic aorta and right atrium. Perfusion medium was pumped backwards through the aortic cannula to the aortic valve and then through blood vessels supplying and draining musculature of the breast and wing. Perfusate exited by way of the cannulated superior vena cava. A detailed description of the surgical procedure is given below.

Chickens were pre-anaesthetized by intramuscular injection of ketamine hydrochloride $(50 \mathrm{mg} / \mathrm{kg})$ before slowly infusing a solution of sodium pentobarbital $(12 \mathrm{mg} / \mathrm{ml}$ solution), heparin (600 units/ml of solution) and saline $(0.9 \% \mathrm{NaCl})$ into the medial tarsal vein. Animals were dosed until they failed to respond to comb pinches and until movement of the third eyelid had ceased. The animal was then anchored in a supine position to a surgical platform by placing strips of adhesive tape around the wings. A superficial midline incision beginning at the caudal point of the sternum and moving cranially toward the neck was made, followed by cannulation of the trachea and gassing of the animal with an $\mathrm{O}_{2} / \mathrm{CO}_{2}(19: 1)$ mixture. The abdominal cavity was opened to allow expansion and eventual bursting of the air sacs. A midline incision was made separating the pectoral muscles from the costal cartilage and bones forming the sternum, thereby exposing the thoracic-abdominal cavity.

The thoracic cavity was held open during the following surgical procedures. Membraneous material along the subclavian arteries and veins ( 1 and 2 respectively; see Fig. 1) and thoracic arteries and veins ( 3 and 4 respectively) was removed to ensure unimpeded blood circulation to the breast and wing regions. With blunt forceps, the thoracic aorta (5) was then isolated by carefully penetrating the right thoracic air sacs and pulling the right lung away from the lateral aspect of the vetebral column. A Mayfield aneuryism clip (6) (Storz Instrument Co., St. Louis, MO, U.S.A.) was placed on the aorta at about the level of the fourth or fifth thoracic vertebra, thus discontinuing arterial blood flow to the abdomen and legs. Next, a loose ligature was placed around the caudal vena cava (7) at the level of the hepatic vein. After bilaterally ligating the common carotid arteries (8) and jugular veins (9), the animal was transected below the level of the aortic clip. Its head also was removed. To obstruct perfusate flow to the ventricles, the heart was reflected and an umbilical tape tie was placed around it at the level of the coronary groove (10). The latter procedure markedly elevated the pressure in the left ventricle, aiding the aortic valve and preventing perfusate from escaping into the pulmonary circulation.

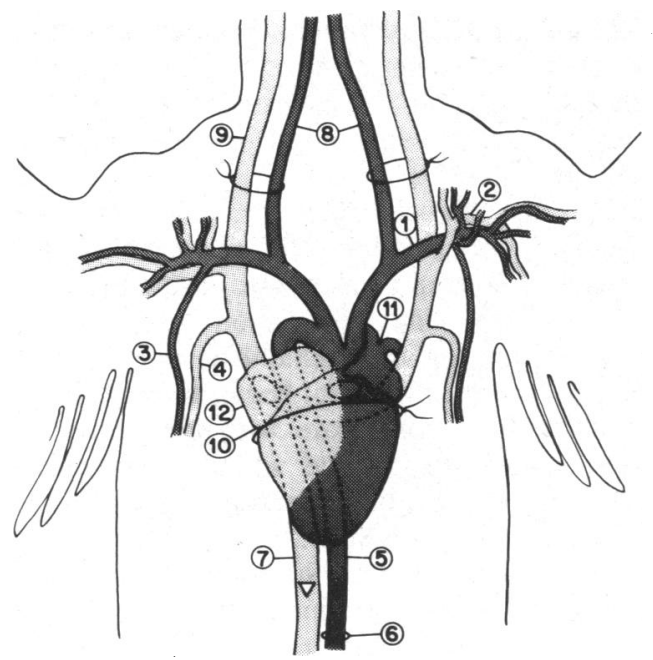

Fig. 1. Surgical diagram for the preparation of perfused breast and wing muscle

Names and numbers of the vessels and anatomical location are as follows: 1 , subclavian arteries; 2 , subclavian veins; 3 , thoracic arteries; 4 , thoracic veins; 5 , aorta; 6 , aneuryism clip; 7 , caudal vena cava; 8, carotid arteries; 9, jugular veins; 10, coronary groove; 11 , left atrium; and 12 , right atrium. See the text for the description of the surgical procedure.

After the removal of connective tissue surrounding the aorta, a small incision ( $\Delta$ ) was made just above the level of the aortic clip. A polyethylene cannula (P.E. 100) attached to the inflow tubing of the perfusion apparatus was inserted into the aorta and tied into place. Next, a nick in the caudal vena cava was made $(\nabla)$ and a $5 \mathrm{~cm}$ cannula (P.E. 380) was inserted into the right atrium (12). The loose ligature previously placed around the caudal vena cava was then tied around this cannula, securing it into place. Perfusion commenced immediately after an umbilical tape tie was placed around the neck of the animal to prevent leakage through the vertebral arteries. The anoxic period (i.e. time from when the ventricles were tied off until re-establishment of circulation) was estimated to be 2-3 min. The entire surgical procedure required 15-18 min.

\section{Perfusion apparatus and sampling of perfusate}

The perfusion apparatus was similar to that described by Goodman et al. (1978) for rat hindquarter perfusion. Throughout the perfusion, pressure at the tip of the aortic cannula was adjusted between 13.3 and $18.6 \mathrm{kPa}(100-140 \mathrm{mmHg})$, which usually produced a flow rate of $35-40 \mathrm{ml} / \mathrm{min}$. The $\mathrm{pH}$ of the perfusion medium was maintained at 
pH 7.55-7.65 by continuous gassing with $\mathrm{O}_{2} / \mathrm{CO}_{2}$ $(19: 1)$ in a membrane-type oxygenator and by addition of $1 \mathrm{M}-\mathrm{NaOH}$ as needed. The entire perfusion apparatus was housed in a Plexiglas cabinet maintained at $42^{\circ} \mathrm{C}$.

After the surgery was complete, the muscle preparation was held in a vertical position and $50 \mathrm{ml}$ of perfusion medium was passed through the tissues and discarded. The preparation was then transferred to the perfusion chamber where an initial perfusate volume of $225 \mathrm{ml}$ began to recycle. Tissue was allowed to equilibrate with the perfusate for $5 \mathrm{~min}$ before a zero-time sample was removed. During the next $90 \mathrm{~min}$ of perfusion, $5 \mathrm{ml}$ samples of perfusate for 3-methylhistidine analysis were taken at $0,15,30,60$ and $90 \mathrm{~min}$. 3-Methylhistidine production was determined by the change in 3-methylhistidine concentration of the perfusate between 30 and $90 \mathrm{~min}$. In addition, $0.5 \mathrm{ml}$ samples of perfusate were taken every $30 \mathrm{~min}$ to assess lactate production and glucose uptake by the perfused tissues. At the end of the sampling period, Methyl Green dye was introduced into the medium to delineate the perfused tissue and determine the quality of perfusion. Skin, feathers, bones and internal organs were later removed from the perfused carcass and the remaining stained muscle tissue was freeze-dried to determine the dry weight of perfused muscle. In these studies the average wet weight of perfused muscle was $75 \mathrm{~g}$.

\section{Analysis of perfusate samples}

The $5 \mathrm{ml}$ perfusate samples were mixed with $6 \%$ (w/v) sulphosalicylic acid. After centrifugation at $12000 \mathrm{~g}$ for $15 \mathrm{~min}$, the supernatant was applied directly to a column of a Beckman 121M amino acid analyser. The analytical procedure for all 3-methylhistidine determinations in the present paper involved a starting buffer of $0.2 \mathrm{M}$-lithium citrate, $\mathrm{pH} 3.70$. After $12 \mathrm{~min}$ the buffer was changed to $1 \mathrm{M}$-lithium citrate, $\mathrm{pH} 3.70$, and 3-methylhistidine eluted $60 \mathrm{~min}$ later. Regeneration was performed by using $0.3 \mathrm{M}$ $\mathrm{LiOH}$. The total run time was $2 \mathrm{~h}$.

In order to determine glucose uptake and lactate production, $0.5 \mathrm{ml}$ perfusate samples were deproteinized in $4.5 \mathrm{ml}$ of $2 \%(\mathrm{w} / \mathrm{v}) \mathrm{HClO}_{4}$ and centrifuged at $2000 \mathrm{~g}$ for $15 \mathrm{~min}$. The supernatant was neutralized with $0.5 \mathrm{M}$-triethanolamine $+3 \mathrm{M}$ $\mathrm{K}_{2} \mathrm{CO}_{3}$. Glucose and lactate concentrations were determined by the methods of Krebs et al. (1963) and Hohorst (1963) respectively.

\section{Evaluating the viability of the breast and wing muscle preparation}

The comparison of tissue ATP, ADP and creatine phosphate concentrations before and after a $60 \mathrm{~min}$ perfusion period was used to assess the viability of the breast and wing muscle preparation.
Muscle samples obtained from the superficial pectoralis of anaesthetized intact chickens were used to determine the concentrations of the above metabolites in vivo. After the breast and wing were perfused for $60 \mathrm{~min}$, bilateral samples of the deep and superficial pectoral muscles were taken. All muscle samples were quickly removed and freezeclamped with Wollenberger tongs previously cooled in liquid $\mathrm{N}_{2}$. Frozen muscle samples were then homogenized in ice-cold $8 \%(\mathrm{w} / \mathrm{v}) \mathrm{HClO}_{4}$ by using a Polytron (Brinkmann Instruments, Westburg, NY, U.S.A.) homogenizer. After centrifugation at $15000 \mathrm{~g}$ for $10 \mathrm{~min}$, the supernatant and one wash were combined and neutralized by addition of $0.5 \mathrm{M}$-triethanolamine $+3 \mathrm{M}-\mathrm{K}_{2} \mathrm{CO}_{3}$. ATP, ADP and creatine phosphate concentrations were determined by enzymic assay (Bergmeyer \& Gawehn, 1974).

Additional information on the viability of the perfused muscle preparation was obtained by measuring: (1) arterial and venous $\mathrm{pO}_{2}$ by oxygen electrode; (2) lactate production; and (3) glucose uptake.

\section{Blood 3-methylhistidine}

In order to determine the concentration of 3-methylhistidine in blood, samples were drawn from the jugular vein into a heparinized syringe and were precipitated with ice-cold $6 \%(\mathrm{w} / \mathrm{v})$ sulphosalicylic acid. After centrifugation of the samples at $10000 \mathrm{~g}$ for $20 \mathrm{~min}$, the supernatant fluids were applied to the amino acid analyser for 3-methylhistidine analysis.

\section{3-Methylhistidine concentration of the myofibrillar and sarcoplasmic protein and free amino acid pool of pectoral muscle}

A $5 \mathrm{~g}$ portion of superficial pectoral muscle excised from the left breast was homogenized in $30 \mathrm{ml}$ of low-ionic-strength buffer $(0.15 \mathrm{M}-\mathrm{NaCl} /$ 5 mM-EDTA/0.01 M- $\mathrm{NaH}_{2} \mathrm{PO}_{4}, \mathrm{pH} 7.7$ ) with a Polytron homogenizer. The muscle homogenate was centrifuged at $5000 \mathrm{~g}$ for $15 \mathrm{~min}$ at $2^{\circ} \mathrm{C}$. As defined by Millward (1970), we assume that the supernatant contains the sacroplasmic proteins and the pellet contains the myofibrillar proteins. The pellet was resuspended in $15 \mathrm{ml}$ of the same buffer and centrifuged as above; this procedure was repeated twice. All supernatants were combined and centrifuged at $100000 \mathrm{~g}$ and $0-4^{\circ} \mathrm{C}$ for $1 \mathrm{~h}$ to precipitate any remaining myofibrillar particles. The sarcoplasmic proteins were then precipitated from this fraction by addition of equal volumes of $6 \%(w / v)$ sulphosalicyclic acid followed by centrifugation; this was repeated twice. The resultant supernatant, containing the free-amino-acid fraction, was desalted on a Dowex 50 column $\left(\mathrm{X8} ; \mathrm{H}^{+}\right.$form) and the effluent freeze-dried. The myofibrillar fraction was resuspended in high-ionic-strength buffer $(0.6 \mathrm{M}$ - 
$\mathrm{NaCl} / 0.01 \mathrm{M}-\mathrm{NaH}_{2} \mathrm{PO}_{4} / 5 \mathrm{~mm}$-EDTA, $\left.\mathrm{pH} 7.7\right)$ and centrifuged at $10000 \mathrm{~g}$ at $0-4^{\circ} \mathrm{C}$ for $30 \mathrm{~min}$ to remove the collagen. The myofibrillar proteins were extracted as crude actomyosin by dialysing the collagen-free supernatant against deionized water for $24 \mathrm{~h}$.

Myofibrillar and sarcoplasmic proteins were hydrolysed in $6 \mathrm{M}-\mathrm{HCl}$ at $110^{\circ} \mathrm{C}$ for $48 \mathrm{~h}$ in sealed ampoules. The hydrolysates were evaporated to dryness in a rotary evaporator. All three fractions were reconstituted in water before applying to the amino acid analyser for 3-methylhistidine determination.

The protein concentration of the myofibrillar and sarcoplasmic fractions was determined by the Biuret method.

\section{3-Methylhistidine in excreta}

Normal and dystrophic chickens were individually housed in stainless-steel wire-floored cages modified for metabolic study. Each animal was 30 days old and weighed approx. $450 \mathrm{~g}$ at the beginning of the experiment. A standard diet containing, by weight, $42 \%$ soya-bean meal, $33 \%$ cornstarch, $10 \%$ cellulose, $8 \%$ soya-bean oil, $2.3 \%$ mineral mix, $2.2 \% \mathrm{CaHPO}_{4}, 1.1 \% \mathrm{CaCO}_{3}, 1.0 \%$ vitamin mix, $0.4 \%$ choline chloride and $0.25 \%$ DLmethionine was fed ad libitum for the entire experiment. This diet did not contain 3-methylhistidine. After an initial adaptation period of 5 days, complete $24 \mathrm{~h}$ excreta collections were obtained from three normal and three dystrophic chickens for the next 3 days.

Fresh excreta samples were homogenized in water with a Polytron homogenizer. The homogenate was centrifuged at $15000 \mathrm{~g}$ for $25 \mathrm{~min}$ and the supernatant was filtered to remove any remaining insoluble material. The filtrate was freeze-dried and redissolved in $30 \mathrm{ml}$ of $6 \mathrm{M}-\mathrm{HCl}$. After hydrolysis for $24 \mathrm{~h}$ at $110^{\circ} \mathrm{C}, \mathrm{HCl}$ was removed by rotary evaporation. The hydrolysate was reconstituted in water before it was applied to the amino acid analyser for 3-methylhistidine determination.

\section{Calculations}

The rate of 3-methylhistidine release in vitro during the perfusion experiments was expressed as nmol of 3-methylhistidine/h per $\mathrm{g}$ of dried muscle. To calculate the fractional degradation rate in vitro for myofibrillar protein, 3-methylhistidine release rate was divided by 3 -methylhistidine content in the muscle and the result multiplied by $24 \mathrm{~h}$. As shown in Table 3 (below), the myofibrillar 3-methylhistidine content of dried pectoral muscle was determined to be 3000 and $2800 \mathrm{nmol} / \mathrm{g}$ of dried muscle for normal and dystrophic chickens respectively. Since these values were not significantly different, the average value of 2900 was used for all calculations. To calculate the fractional degradation rate in vivo for myofibrillar protein, the amount of 3-methylhistidine excreted per day was divided by 3-methylhistidine/g body weight. The body 3methylhistidine pool was $208 \mathrm{nmol}$ of 3-methylhistidine/g body weight, based on our observation that chicken skeletal muscle was $20 \%$ dry weight and the assumptions: (1) that the average 3-methylhistidine content of skeletal muscle was $2900 \mathrm{nmol} / \mathrm{g}$ of dried muscle, and (2) that skeletal muscle represented $36 \%$ of the total body weight in both normal and dystrophic chickens. The first assumption was derived from data for white pectoral muscle and probably overestimated the average 3-methylhistidine concentration of chicken skeletal muscle. It has been shown that red muscle, which comprises a substantial portion of the chicken carcass, contains significantly less myofibrillar 3-methylhistidine than white muscle (Johnson \& Perry, 1970; Kuehl \& Adelstein, 1970). To check the validity of the second assumption, the ratio, eviscerated-carcass weight (total carcass minus entrails) per unit body weight was compared between lines 412 and 413 in 4-week-old chicks (D. W. Peterson, personal communication). A value of $80 \%$ was calculated for both normal and dystrophic chickens. This calculation assumed that the weight of the feathers, skin, and bones were the same for both lines. It was concluded that both lines of chickens were composed of the same relative amount of skeletal muscle, even though dystrophic chickens exhibit a marked hypertrophy of the pectoralis at this age. The percentage of skeletal muscle of an intact chicken was assigned the value $36 \%$ on the basis of results obtained by Mitchell et al. (1926) for young cockerels.

\section{Statistical procedures}

Data was statistically evaluated by conventional one-way analysis of variance and the Student's $t$ test. Significant differences between means in Table 3 were determined by using Duncan's multiple-range test (Steel \& Torrie, 1960).

\section{Results}

\section{Viability of the breast and wing muscle preparation}

In Table 2, ATP, ADP and creatine phosphate concentrations in vivo and in vitro are presented for pectoral muscle from normal and dystrophic chickens. Since the concentration of the above organic phosphate compounds did not vary with the sampling location (superficial versus deep or uncut versus cut muscle groups), the values calculated for each chicken represent the mean of four muscle samples taken from each animal. After $60 \mathrm{~min}$ of perfusion, the ATP, ADP and creatine phosphate concentrations in perfused breast and wing muscles were similar to those observed in vivo 
Table 2. Parameters of viability for the perfused breast and wing muscle preparation

Organic phosphate concentrations in perfused breast muscle were determined after $60 \mathrm{~min}$ of perfusion. The organic phosphate contents of four separate samples from each perfused preparation were averaged and used as the value for each bird. Organic phosphate concentrations in vivo in breast muscle were determined in chickens anaesthetized with pentobarbital. Lactate output and glucose uptake by perfused preparations were measured between 30 and 90 min of perfusion. All entries in the Table represent the mean \pm S.E.M. for the number of birds shown in parentheses. Statistical significance at $P<0.05, P<0.01$ and $P<0.02$ from normal line 412 (in vivo) is indicated by the superscripts ${ }^{A},{ }^{B}$ and ${ }^{C}$ respectively.

\section{Group}

Normal 412 in vitro (2)

Normal 412 in vivo (4)

Dystrophic 413 in vitro (2)

Dystrophic 413 in vivo (4)
[ATP]

( $\mu \mathrm{mol} / \mathrm{g}$ wet wt.)

$6.56 \pm 0.22$

$6.83 \pm 0.98$

$4.04 \pm 0.14$

$3.74 \pm 0.36^{\wedge}$
[ADP]

( $\mu \mathrm{mol} / \mathrm{g}$ wet wt.)

$0.63 \pm 0.02$

$0.56 \pm 0.04$

$0.53 \pm 0.02$

$0.45 \pm 0.03$
[Creatine phosphate] ( $\mu \mathrm{mol} / \mathrm{g}$ wet wt.)

$13.85 \pm 0.15$

$17.40 \pm 2.50$

$5.62 \pm 1.58$

$5.36 \pm 1.80^{\mathrm{C}}$
Lactate output Glucose uptake $(\mu \mathrm{mol} / \mathrm{h}$ per $\mathrm{g} \quad(\mu \mathrm{mol} / \mathrm{h}$ per $\mathrm{g}$

of dried muscle) of dried muscle)

$92.9 \pm 10.2(7) \quad 48.4 \pm 4.2(7)$

$128.5 \pm 7.5^{\mathrm{B}}(8) \quad 59.0 \pm 6.6(8)$

Table 3. 3-Methylhistidine content of the myofibrillar, sarcoplasmic and free-amino-acid fractions in pectoral muscle and in the blood of normal and dystrophic chickens

Blood and breast muscle samples were taken from 30-day-old normal and dystrophic chickens and analysed for 3-methylhistidine as described in the Methods and materials section. The values represent the mean \pm S.E.M. for the number of measurements shown in parentheses. Significant difference from normal line $412(P<0.03)$ is indicated by ${ }^{A}$.

3-Methylhistidine content ( $\mathrm{nmol} / \mathrm{g})$

\section{Chicken}

Normal 412 (4)

Dystrophic 413 (4)

\begin{tabular}{|c|c|}
\hline \multicolumn{2}{|c|}{ Myofibrillar fraction } \\
\hline $\begin{array}{l}\text { Myofibrillar } \\
\text { protein }\end{array}$ & $\begin{array}{c}\text { Dried } \\
\text { muscle }\end{array}$ \\
\hline $\begin{array}{l}4910 \pm 140 \\
4220 \pm 160^{A}\end{array}$ & $\begin{array}{l}3000 \pm 100 \\
2800 \pm 110\end{array}$ \\
\hline
\end{tabular}

Sarcoplasmic fraction

$\overbrace{\text { Sarcoplasmic Dried }}^{\text {Sarcoplas }}$

protein muscle

$35 \pm 4 \quad 15 \pm 3$

$38 \pm 3 \quad 13 \pm 2$

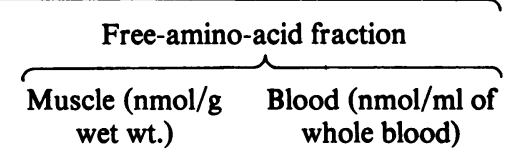

$18.9 \pm 1.6$

$27.0 \pm 2.4^{\wedge}$

$19.0 \pm 2.0(10)$

$19.6 \pm 1.4(10)$ in both normal and dystrophic muscles. However, creatine phosphate concentrations in muscle from dystrophic (line 413) chickens were one-third of those in normal chickens (line 412), and ATP concentrations in muscles from dystrophic chickens were significantly lower than those in normal birds. Between 30 and $90 \mathrm{~min}$ of perfusion, rates of glucose uptake and lactate production were constant in both normal and dystrophic preparations.

In dystrophic preparations, lactate production was significantly increased over the normal value. Although glucose uptake was also increased in dystrophic birds, this increase was not significantly different from the normal value (Table 2). The arterial and venous oxygen tensions $\left(\mathrm{pO}_{2}\right)$ of the perfusate were constant during the first $60 \mathrm{~min}$ of perfusion and averaged 45.3 and $14.7 \mathrm{kPa}$ (340 and $110 \mathrm{mmHg}$ ) respectively.

3-Methylhistidine content of the myofibrillar, sarcoplasmic and free-amino-acid fractions in pectoral muscle and in the blood of normal and dystrophic chickens

An analysis of the 3-methylhistidine composition of various components of muscle was conducted with homogenates of pectoral muscle. The results are summarized in Table 3. More than $96 \%$ of the total 3-methylhistidine in this muscle was associated with the myofibrillar protein fraction. The low concentrations of 3-methylhistidine detected in the sarcoplasmic proteins were probably due to myofilbrillar contamination. In dystrophic muscle, the 3-methylhistidine content of myofibrillar protein (nmol/g of myofibrillar protein) was significantly lower than in normal muscle. However, when expressed as $\mathrm{nmol} / \mathrm{g}$ of dried muscle, myofibrillar 3-methylhistidine concentration was similar in both normal and dystrophic muscle. Further investigation revealed that the amount of free 3-methylhistidine ( $\mathrm{nmol} / \mathrm{g}$ wet weight) was elevated in dystrophic muscle, whereas blood 3-methylhistidine concentrations were not significantly different between normal and dystrophic chickens.

\section{3-Methylhistidine release from perfused breast and wing muscle}

In preliminary experiments, a time course of 3-methylhistidine release from perfused breast and wing muscle was conducted with normal and untreated dystrophic chickens (Fig. 2). During the 
first $30 \mathrm{~min}$ of perfusion, a high rate of release of 3-methylhistidine occurred. We assume this represents release of 3-methylhistidine from extracellular

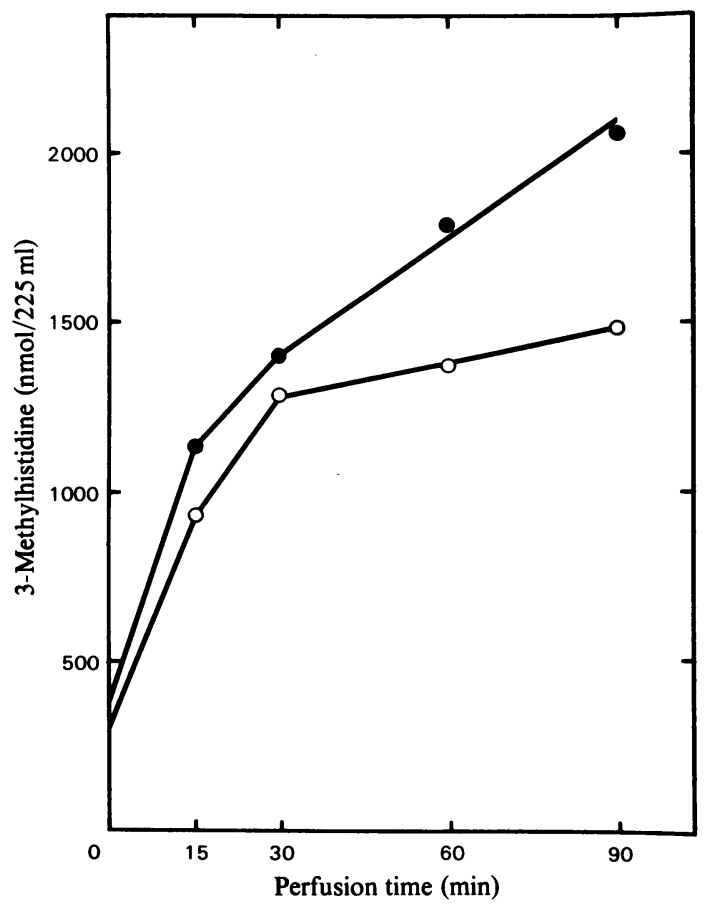

Fig. 2. Time course of 3-methylhistidine release from perfused breast and wing muscle

Normal (O) and dystrophic (O) breast and wing muscle preparations were perfused for $90 \mathrm{~min}$ after an initial $5 \mathrm{~min}$ equilibration period. Perfusate samples were taken at $0,15,30,60$ and 90 min for 3-methylhistidine analysis. Each point represents the mean value for four perfusions. tissue spaces. Between 30 and 90 min of perfusion, total 3-methylhistidine production increased at a linear rate in both groups of animals. It is assumed that, during the 30-90 min interval, 3-methylhistidine release directly reflects changes in intracellular 3-methylhistidine pools that are the direct result of myofibrillar protein degradation. In later experiments, the 3-methylhistidine release rate was determined by subtracting the amount of 3-methylhistidine in the $30 \mathrm{~min}$ sample from that in the $90 \mathrm{~min}$ sample and using the difference to calculate the degradation rate in vitro of myofibrillar protein.

In Table 4, 3-methylhistidine release from perfused breast and wing muscle was monitored in four groups of chickens: (1) normal line 412, (2) dystrophic line 413, (3) methylsergide-treated dystrophic line 413, and (4) diphenylhydantoin-treated dystrophic line 413 . When compared with normal controls, untreated dystrophic chickens exhibited a 2 -fold increase in the rate of 3-methylhistidine release ( $\mathrm{nmol} / \mathrm{h}$ per $\mathrm{g}$ of dried muscle). This is further illustrated in Fig. 2, where the slope of the linear portion of the curve for the dystrophic group is greater than that for the normal group. On the basis of these data, the fractional degradation rate in vitro and half-life of myofibrillar protein in normal and dystrophic muscle were calculated to be $12.1 \%$ day (5.7 days) and $23.8 \%$ /day (2.9 days) respectively. 3-Methylhistidine release from dystrophic muscle was unaltered by either methylsergide or diphenylhydantoin drug treatment, hence it remained significantly higher than that of normal muscle.

\section{3-Methylhistidine excretion in vivo}

Daily 3-methylhistidine excretion rates were increased significantly in untreated dystrophic chickens [normal line $412,7.3 \pm 0.2$ and dystrophic

Table 4. 3-Methylhistidine release from perfused breast and wing muscle of normal, dystrophic and dystrophic drug-treated chickens

The perfusion medium described in Table 1 was recycled through the breast and wing muscles of 26-34-day-old chickens. The 3-methylhistidine release rate was determined by the change in 3-methylhistidine concentration of perfusate between 30 and $90 \mathrm{~min}$ of perfusion. The fractional degradation rate in vitro of myofibrillar protein $\left(K_{\mathrm{d}}\right)$ was calculated by dividing the rate of 3-methylhistidine release by the myofibrillar 3-methylhistidine content of breast muscle. For further details of the perfusion procedure and $K_{\mathrm{d}}$ calculations, see the text. Drug-treated chickens were injected intraperitoneally with either diphenylhydantoin or methylsergide. The dosage schedules are given in the text. The values represent the mean \pm S.E.M. 3-Methylhistidine release is shown for the number of chickens given in parentheses. Significant difference from normal line $412(P<0.05)$ is indicated by ${ }^{A}$.

$\begin{array}{lcc} & \begin{array}{c}\text { 3-Methylhistidine release } \\ \text { (nmol/h per g of dried muscle) }\end{array} & \begin{array}{c}K_{\mathrm{d}} \\ (\% / \text { day })\end{array} \\ \text { Normal (12) } & 14.7 \pm 2.5^{\mathrm{A}} & 12.1 \\ \text { Dystrophic (13) } & 28.9 \pm 3.9^{\mathrm{A}} & 23.8 \\ \text { Dystrophic drug-treated } & & \\ \quad \text { Methylsergide (6) } & 27.4 \pm 3.8^{\mathrm{A}} & 22.7 \\ \text { Diphenylhydantoin (7) } & 25.0 \pm 2.0^{\mathrm{A}} & 20.7\end{array}$


line $413,10.0 \pm 0.1 \mathrm{nmol} \cdot \mathrm{day}^{-1} \cdot(\mathrm{g} \text { body } \mathrm{wt})^{-1}$; $P<0.02$ ]. From these data, the fractional degradation rates in vivo and half-lives of myofibrillar protein from normal and dystrophic chickens were calculated to be $3.5 \% /$ day (19.7 days) and $4.8 \% /$ day (14.3 days), respectively.

\section{Discussion}

The perfused breast and wing muscle preparation is a viable system for biochemical and physiological experimentation. Gross signs of muscle oedema were not observed during the $90 \mathrm{~min}$ perfusion period. After $60 \mathrm{~min}$ of perfusion, ATP, ADP and creatine phosphate concentrations in pectoral muscle were not significantly different from muscle freezeclamped in vivo. With a flow rate of $35 \mathrm{ml} / \mathrm{min}$, the non-erythrocyte perfusion medium provided adequate oxygenation to the tissues. Venous $\mathrm{pO}_{2}$ never fell below $13.3 \mathrm{kPa}(100 \mathrm{mmHg})$; hence the presence of haemoglobin in the medium for oxygen transport was not necessary. Rates of glucose uptake and lactate production were constant throughout the entire course of the perfusion. In addition, we measured the lactate/pyruvate ratio and found it to be similar in freeze-clamped muscle from normal and dystrophic preparations. This indicates that the cytoplasmic redox state is not affected by dystrophy and that muscle tissue from both groups of chickens was oxygenated to a similar extent.

In Table 2, differences in the concentrations of ATP and creatine phosphate in vivo were observed between pectoral muscles from normal and dystrophic chickens. Similar findings have been reported in the dystrophic mouse (Zymaris et al. 1959) and human (Bonetti et al., 1954). The reason why dystrophic chickens have lowered ATP and creatine phosphate concentrations is not known, but may be the result of a lowered respiratory-control ratio with cytoplasmically generated substrates such as pyruvate, as suggested by Ashmore \& Doerr (1970).

In dystrophic chickens, the rates of myofibrillar protein degradation in vitro and in vivo, as measured by 3-methylhistidine excretion, were elevated 2.0 and 1.35-fold respectively when compared with normal birds. We can offer no simple reason for this discrepancy, or for the observed discrepancy between calculated degradation rates in vivo and in vitro. In regard to the effects of muscular dystrophy on myofibrillar degradation rates, the dystrophic process is limited to white muscle in chickens. Most of the muscles perfused in the experiments in vitro were white muscles; therefore this system is likely to more sensitively reflect the effects of dystrophy than whole-body measurements, where white muscle comprises about $40 \%$ of the total skeletal muscle mass of 4-week-old dystrophic chickens.
When comparing the calculated myofibrillar protein degradation rate in vitro for perfused muscles from normal chickens with the corresponding value in vivo, a 3-4-fold difference is seen. Three possible explanations for this descrepancy are offered: (1) myofibrillar protein degradation is more rapid in pectoral and wing muscles in relation to the average rate for the whole animal; (2) due to non-specific stress factors, muscle protein turnover is enhanced in the preparation in vitro; and (3) the calculated 3-methylhistidine pool size in vivo is an overestimate. Since Cowgill \& Freeburg (1957) showed that labelled 3-methylhistidine was quantitatively excreted in the excreta of chickens, it therefore seems unlikely, but not impossible, that incomplete excretion or oxidation of 3-methylhistidine can account for the discrepancy between rates of degradation in vivo and in vitro.

Concerning the first explanation, it is doubtful that myofibrillar protein turnover varies greatly between different muscles. The degradation rate in vivo for mixed proteins of pectoral and leg muscles was similar in 2-week-old chicks (Maruyama et al., 1978). The second suggestion may partially explain the above discrepancy, since increased muscle protein catabolism and net protein loss is observed in the perfused rat hemicorpus when the perfusate is not supplemented with insulin (Jefferson et al., 1977). Lastly, as discussed in the Methods and materials section, it is likely that the calculated 3-methylhistidine pool size in vivo is an overestimate, thereby underestimating the fractional degradation rate in vivo.

By using the difference between the synthetic rate and the growth rate of muscle protein, MacDonald \& Swick (1981) calculated the average degradation rate in vivo of mixed proteins in pectoral muscles of 2-7-week-old Leghorn chickens to be $13.5 \% /$ day. The degradation rate of myofibrillar protein calculated from 3-methylhistidine release in perfusion in vitro of normal chickens (Table 4) closely agrees with the rate calculated by MacDonald \& Swick (1981). Since the average degradation rate of myofibrillar and sarcoplasmic fractions is similar in muscles from chickens (Laurent et al., 1978a), a comparison with the work of MacDonald \& Swick (1981) seems valid. In the only report in the literature concerning protein degradation in the dystrophic chicken, Rourke (1975) reported that the degradation rate of myosin in pectoralis muscles from 2-3-week-old dystrophic chickens was $14.5 \% /$ day. In that study, Rourke (1975) was unable to demonstrate that myosin was degraded in normal chickens, which conflicts with the results presented in Table 4. Radioisotope re-utilization in chicken skeletal muscle has been demonstrated by Laurent \& Sparrow (1977) and MacDonald \& Swick (1981). Since Rourke (1975) did not take precautions to 
minimize radioisotope re-utilization, it is likely that degradation rates reported in that paper are incorrect and underestimate the actual rates.

In the muscular-dystrophic chicken, a transient gross hypertrophy of the pectoral muscle occurs early in life, followed by atrophy and replacement of lost muscle with fat as the animal fully matures. At 6 weeks of age, dystrophic pectoral muscle is 1.5 times the size of normal pectoral muscle (Wilson et al., 1979). When analysis was done on a whole-muscle basis, there was a higher absolute protein content in dystrophic pectoral muscle (Holliday et al., 1968). At the cellular level, the gross hypertrophy seen in dystrophic muscle is first the result of a cellular hypertrophy as manifested by increased fibre size (Holliday, 1965). This is followed by fibre hyperplasia in chickens older than 6 weeks. In order for true hypertrophy to occur, there must be a higher relative increase in muscle protein synthesis in comparison with muscle protein degradation. On the basis of the incorporation of $\left[{ }^{14} \mathrm{C}\right]$ valine, Weinstock et al. (1969) reported an apparent 2-fold stimulation in the rate of myofibrillar protein synthesis in vivo and in vitro of dystrophic pectoral muscle when compared with normal muscle. Weinstock et al. (1969) assumed that the free valine pools were identical in normal and dystrophic muscles. In fact, the valine pool size is increased $70 \%$ in dystrophic muscle (Peterson et al., 1963). Therefore the reported elevation in myofibrillar protein synthesis in dystrophic chickens would be underestimated, owing to greater dilution of radioisotope in dystrophic compared with normal muscle. On the basis of 3-methylhistidine release in vivo and in vitro, we estimate that myofibrillar protein degradation is elevated 1.35-2-fold by dystrophy. If the 2-fold increase in synthetic rates calculated by Weinstock et al. (1969) is an underestimate, then it is clear that hypertrophy should occur.

Hypertrophy of dystrophic pectoral muscle has several morphological and histological characteristics in common with stretch-induced growth of the anterior latissumus dorsi muscle (Holliday, 1965; Sola et al., 1973). As in dystrophic pectoral muscle, both protein synthesis and degradation are elevated in stretch-induced hypertrophy of wing muscle, the former process to a greater extent than the latter (Laurent et al., 1978b; Laurent \& Millward, 1980). In both of these models of muscle hypertrophy, the increased protein degradation represents an inherent inefficiency in muscle growth for which the physiological significance is not clearly understood.

Associated with the increased rates of protein degradation in dystrophic muscle is the elevation in activity of lysosomal cathepsins A, B, C and D (Iodice et al., 1972; Peterson et al., 1972). During early development of normal breast muscle after hatching, cathepsin activity is initially high and gradually declines as growth slows, whereas in hypertrophied dystrophic pectoral muscle, cathepsin activity remains elevated. Recent studies indicate that the lysosomal cathepsins may be involved in myofibrillar protein degradation. Schwartz \& Bird (1977) demonstrated that cathepsins B and D can degrade purified myofibrillar protein in vitro. In tissue cultures of normal and dystrophic embryonicchick muscle, leupeptin and pepstatin, inhibitors of cathepsins B and D respectively, were shown to act intracellularly to retard degradation of myofibrils as well as decrease proteolytic activity (McGowan et al., 1976; Stracher et al., 1979).

In early studies, it was shown that myosin of both normal and dystrophic pectoral muscle exhibited molecular weights, isoelectric points, salt-sensitivities, enzymic activities and amino acid compositions (Báràny et al., 1966; Morey et al., 1968). More recently, Stracher et al. (1979) reported that myosin from dystrophic and embryonic chickens contained less light-chain 3 than normal birds and suggested that 'dystrophic' myosin might be embryonic in nature and more susceptible to proteolysis. This is consistent with the observation that elevated rates of muscle protein degradation are seen in both dystrophic chickens (Table 4) and immature post-hatched chicks younger than 2 weeks of age (Maruyama et al., 1978).

Amino acid analysis of pectoral muscle revealed that 'dystrophic' myofibrillar protein contained significantly less 3-methylhistidine than did normal muscle (Table 3). Embryonic actin and myosin also contain less 3-methylhistidine (Trayer et al., 1968; Krzysik et al., 1971). This finding supports the hypothesis that hereditary muscular dystrophy in the chicken represents a delay or defect in the normal maturation and development of muscle (Morgan \& Herrmann, 1965; Weinstock \& Lukacs, 1965; Cosmos, 1970).

As in the rat (Haverberg et al., 1974) and human (Bilmazes et al., 1978), peptide-bound 3-methylhistidine is restricted to the myofibrillar fraction of pectoral muscle of the chicken. Since the percentage dry weight of muscle and the 3-methylhistidine concentration of muscle is similar in normal and dystrophic chickens, differences in the 3-methylhistidine excretion rate truly reflect altered rates of myofibrillar protein catabolism. On the basis of results obtained for one chicken, Asatoor \& Armstrong (1967) reported the 3-methylhistidine content of breast muscle to be $2.34 \mu \mathrm{mol} / \mathrm{g}$ of dried muscle protein, which is similar to the value in Table 3. Elevated amounts of free 3-methylhistidine in dystrophic muscle are probably the result of increased proteolysis in this tissue. In contrast, the blood 3-methylhistidine concentration is similar in normal and dystrophic chickens. Apparently 3methylhistidine released from muscle is greatly 
diluted in the large blood amino acid pool and is rapidly excreted by way of the kidney or gastrointestinal tract. Fisher et al. (1975) reported the free 3-methylhistidine pool size of breast muscle of adult cockerels to be 1000 times greater than our values (Table 3). Our data do not support the hypothesis that the chicken stores 3-methylhistidine in its breast muscle, as was suggested by Fisher et al. (1975).

Similar anatomical, histopathological and biochemical characteristics between avian and human muscular dystrophy previously have been described in detail (Julian \& Asmundson, 1963; Asmundson et al., 1966; Mendell et al., 1979). The results of the present study support the hypothesis that muscle protein turnover is also similar in dystrophic humans and chickens. McKeran et al. (1979) reported that myofibrillar protein degradation, as measured by 3-methylhistidine excretion in urine, was elevated 3-fold in patients afflicted with Duchenne muscular dystrophy. Increased activities of lysosomal cathepsins $\mathrm{A}, \mathrm{B}, \mathrm{C}$ and $\mathrm{D}$ are also observed in these patients (Pearson \& Kar, 1979). These observations lend credence to the dystrophic chicken as a valid model for studying alterations in protein metabolism in human neuromuscular disease.

Recently, diphenylhydantoin, an anti-convulsant drug, and methylsergide, a serotonin antagonist, have been shown to improve righting ability and certain biochemical parameters in dystrophic chickens (Bhargava et al., 1977; Entriken et al., 1978). In the present study, neither diphenylhydantoin nor methylsergide drug treatment had a significant effect on the rate of myofibrillar protein degradation in vitro in dystrophic chickens. Apparently, these drugs act through common or separate mechanisms not involving alterations in muscle protein metabolism. Stracher et al. (1978, 1979) reported that intramuscular injection of the proteinase inhibitors leupeptin and pepstatin was effective in delaying degeneration of dystrophic muscle in vivo, although righting ability was unchanged by this treatment. Since improved muscle function in dystrophic chickens can be achieved without altering muscle protein degradation and vice versa, increased myofibrillar protein catabolism is probably secondary to the unknown primary disorder of hereditary muscular dystrophy in the chicken.

This work was supported mainly by Biomedical Research Support Grant no. RR05457 from the U.S. National Institutes of Health. A. S. W. was partially supported by a Summer Fellowship from the California Foundation for Biochemical Research. We thank Dr. R. A. Freedland, Dr. L. M. Julian and Dr. D. W. Peterson for their helpful discussions during the course of this investigation.

\section{References}

Asatoor, A. M. \& Armstrong, M. D. (1967) Biochem. Biophys. Res. Commun. 26, 168-174

Ashmore, C. R. \& Doerr, L. (1970) Biochem. Med. 4, 246-259

Asmundson, V. S., Kratzer, S. H. \& Julian, L. M. (1966) Ann. N. Y. Acad. Sci. 138, 49-60

Bárány, M., Gaetjens, E. \& Bárány, K. (1966) Ann. N. Y. Acad. Sci. 138, 360-366

Bergmeyer, H.-U. \& Gawehn, K. (1974) Methods of Enzymatic Analysis, 2nd edn., vol. 4, Academic Press, London and New York

Bhargava, A. K., Barnard, E. A \& Hudecki, M. S. (1977) Exp. Neurol. 55, 583-602

Bilmazes, C., Uauy, R., Haverberg, L. N., Munro, H. N. \& Young, V. R. (1978) Metab. Clin. Exp. 27, 525-530

Bonetti, E., Toschi, F. N. \& Levi, M. (1954) Sperimentale 104, Fasc. X1-X11 315

Cosmos, E. (1970) in The Physiology and Biochemistry of Muscle as a Food (Cassens, R. G., Briskey, E. J. \& Marsh, B. B., eds.), vol. 2, pp. 193-207, University of Wisconsin Press, Madison

Cowgill, R. W. \& Freeburg, B. (1957) Arch. Biochem. Biophys. 71, 466-472

Entriken, R. K., Patterson, G. T., Weidoff, P. M. \& Wilson, B. W. (1978) Exp. Neurol. 61, 650-663

Fisher, H., Konlande, J. \& Strumeyer, D. (1975) Nutr. Metab. 18, 120-126

Goodman, M. N., Ruderman, N. B. \& Aoki, T. T. (1978) Diabetes 27, 1065-1075

Haverberg, L. N., Munro, H. N. \& Young, V. R. (1974) Biochim. Biophys. Acta 371, 226-237

Hillgartner, F. B., Williams, A. S., Flanders, J. \& Hansen, R. J. (1980) Fed. Proc. Fed. Am. Soc. Exp. Biol. 39, 416

Hohorst, H. U. (1963) in Methods of Enzymatic Analysis (Bergmeyer, H.-U., ed.), pp. 266-270, Academic Press, New York

Holliday, T. A. (1965) Ph.D. Thesis, University of California, Davis

Holliday, T. A., Julian, L. M. \& Asmundson, V. S. (1968) Anat. Rec. 160, 207-216

Iodice, A. A., Chin, J., Perker, S. \& Weinstock, I. M. (1972) Arch. Biochem. Biophys. 152, 166-174

Jefferson, L. S., Li, J. B. \& Rannels, S. R. (1977) J. Biol. Chem. 252, 1476-1483

Johnson, P. \& Perry, S. V. (1970) Biochem. J. 119, 293-298

Julian, L. M. \& Asmundson, V. S. (1963) in Muscular Dystrophy in Man and Animals (Bourne, G. H. \& Golarz, M. N., eds.), pp. 447-498, S. Karger, New York

Krebs, H. A., Bennett, D. A. H., deGasquet, P., Gascoyne, T. \& Yoshida, T. (1963) Biochem. J. 86, 22-27

Krzysik, B., Vergnes, J. P. \& McManus, I. R. (1971) Arch. Biochem. Biophys. 146, 34-45

Kuehl, W. N. \& Adelstein, R. S. (1970) Biochem. Biophys. Res. Commun. 39, 956-964

Laurent, G. J. \& Millward, D. J. (1980) Fed. Proc. Fed. Am. Soc. Exp. Biol. 39, 42-47

Laurent, G. J. \& Sparrow, M. P. (1977) Growth 41, 249-262 
Laurent, G. J., Sparrow, M. P., Bates, P. C. \& Millward, D. J. (1978a) Biochem. J. 176, 393-405

Laurent, G. J., Sparrow, M. P. \& Millward, D. J. (1978b) Biochem. J. 176, 407-417

MacDonald, M. L. \& Swick, R. W. (1981) Biochem. J. in the press

Maruyama, K., Sunde, M. L. \& Swick, R. W. (1978) Biochem. J. 176, 573-582

McGowan, E. B., Shafig, S. A. \& Stracher, A. (1976) Exp. Neurol. 50, 649-657

McKeran, R. O., Halliday, D., Purkiss, P. \& Royston, P. (1979) J. Neurol. Neurosurg. Psych. 42, 536-541

Mendell, J. R., Higgins, R., Sahenk, Z. \& Cosmos, E. (1979) Ann. N.Y. Acad. Sci. 317, 409-430

Millward, D. J. (1970) Clin. Sci. 39, 577-590

Mitchell, H. H., Card, L. E. \& Hamilton, T. S. (1926) Ill. Agric. Exp. Station Bull. 278, 1-132

Morey, K. S., Tarczy-Hornoch, K. \& Brown, W. D. (1968) Arch. Biochem. Biophys. 124, 521-529

Morgan, D. F. \& Herrmann, H. (1965) Proc. Soc. Exp. Biol. Med. 120, 68-72

Pearson, C. M. \& Kar, N. C. (1979) Ann. N.Y. Acad. Sci. 317, 465-477

Peterson, D. W., Lilyblade, A. L. \& Lyon, J. (1963) Proc. Soc. Exp. Biol. Med. 113, 798-802

Peterson, D. W., Lilyblade, A. L. \& Bond, D. C. (1972) Proc. Soc. Exp. Biol. Med. 141, 1056-1062
Rourke, A. W. (1975) J. Cell. Physiol. 86, 343-352

Schwartz, W. N. \& Bird, J. W. C. (1977) Biochem. J. 167, 811-820

Sola, O. M., Christensen, D. L. \& Martin, A. W. (1973) Exp. Neurol. 41, 76-100

Steel, R. G. D. \& Torrie, J. H. (1960) Principles and Procedures of Statistics, pp. 107-114, McGraw-Hill Book Co., New York

Stracher, A., McGowan, E. B. \& Shafig, S. A. (1978) Science 407, 50-51

Stracher, A., McGowan, E. B., Siemankowski, L., Molak, V. \& Shafig, S. A. (1979) Ann. N.Y. Acad. Sci. 317, 349-355

Trayer, I. P., Harris, C. J. \& Perry, S. V. (1968) Nature (London) 217, 452-453

Weinstock, I. M. \& Lukacs, M. (1965) Enzymol. Biol. Clin. 5, 103-112

Weinstock, I. M., Soh, T. S., Freedman, H. A. \& Cutler, M. E. (1969) Biochem. Med. 2, 345-356

Wilson, B. W., Randall, W. R., Patterson, G. T. \& Entriken, R. K. (1979) Ann. N.Y. Acad. Sci. 317, 224-246

Young, V. R., Alexis, S. D., Baliga, B. S., Munro, H. N. \& Muecke, W. (1972) J. Biol. Chem. 247, 3592-3600

Zymaris, M. C., Epstein, N., Saifer, A., Aronson, S. M. \& Volk, B. W. (1959) Am. J. Physiol. 196, 10931097 